\title{
DOSSIÊE
}

\section{Princípio federativo e conflitos de competências constitucionais:}

\section{uma análise sob o enfoque da gestão de crise da saúde pública na Pandemia de Covid-19}

Arilson Garcia Gil ${ }^{1}$

Como citar este artigo: GIL, Arilson Garcia. Princípio federativo e conflitos de competências constitucionais: uma análise sob o enfoque da gestão de crise da saúde pública na Pandemia de Covid-19. Revista de Ciências do Estado. Belo Horizonte: v. 6, n. 1, 2021, e25986. ISSN: $2525-8036$.

Resumo: O presente trabalho analisa o conflito de competências constitucionais instaurado entre entes federados na Pandemia de Covid-19 e a interpretação dada pelo Supremo Tribunal Federal sobre o tema. O trabalho parte do estudo do Princípio Federativo como vetor de interpretação da Constituição e passa pela análise da divisão de competências constitucionais e sua importância para a autonomia dos entes federados. Também são analisados os dispositivos da Lei Federal $\mathrm{n}^{\circ} 13.979 / 2020$ que geraram debate sobre o conflito de competências para regulamentação e atuação na Pandemia. No curso da pesquisa verificou-se que as normas constitucionais que tratam da saúde pública e as normas infraconstitucionais editadas para enfrentamento da Pandemia de Covd-19 configuram atribuição e exercício de competência legislativa concorrente e competência administrativa comum. Por fim, tratou-se da interpretação conforme a Constituição dada à Lei Federal $n^{\circ}$ 13.979/2020 pelo Supremo Tribunal Federal, ao declarar a competência dos Estados e dos Municípios para regulamentar medidas como a quarentena, independente de autorização da esfera federal. Conclui-se pela adequação da referida decisão ao federalismo constitucional, além de ser esclarecido que referida decisão não configurou reconhecimento de responsabilidade exclusiva dos Estados e dos Municípios no combate ao Covid-19, diante da distinção entre competência legislativa e competência administrativa, bem como da estruturação do Sistema Único de Saúde com participação de todos os entes federados.

Palavras-chave: Princípio Federativo; Saúde Pública; Gestão de Crise; Competência Legislativa; Competência Administrativa.

\footnotetext{
${ }^{1}$ Mestrando em Direito Constitucional pela PUC-SP. Especialista em Direito Constitucional pela USP e em Direito Tributário pela PUC-SP. Bacharel em Direito pela UNESP. Professor da UNIP. Procurador do Estado de São Paulo. Contato: arilsongil@ hotmail.com
} 
Recebido em 24.10.2020

Aprovado em 03.05.2021

Publicado em 17.05.2021

\section{INTRODUÇÃO}

O ano de 2020 ficará marcado na história pelo desafio do enfrentamento mundial da Pandemia de Covid-19. A gestão desse desafio tem sido intensa e complexa diante do desconhecimento de formas cientificamente comprovadas de combate ao vírus e da facilidade e da velocidade de transmissão da doença. Nesse contexto, a quarentena foi a medida necessária para impedir o colapso dos sistemas de saúde e, em razão de seus graves impactos econômicos, gerou forte debate público sobre os termos de sua implementação e de sua flexibilização.

No Brasil não poderia ser diferente, com alguns agravantes notórios: seu extenso território, seu número de habitantes e sua diversidade de contextos social e econômico. É certo, porém, que o Brasil tem alguns fatores a seu favor, em especial seu sistema de Seguridade Social. Com efeito, há previsão de um Sistema Único de Saúde de acesso universal assegurado constitucionalmente e cuja implementação é dever da governança do Estado de forma descentralizada em todas as esferas de governo, com a participação da comunidade e demais organizações privadas da sociedade organizada, nos termos do artigo 196, 197 e 198, da Constituição Federal; há também a previsão de sistemas de Previdência e Assistência Sociais que podem ser geridos para mitigar os efeitos da crise econômica que se instala em decorrência das medidas tomadas para enfrentamento da Pandemia, conforme artigos 201 e seguintes também da Constituição.

Vê-se que o Sistema Único de Saúde é uma rede regionalizada e hierarquizada cuja gestão exige orçamento, regulamentação normativa e governança administrativa em todas as esferas de governo (federal, estadual, distrital e municipal). Diante dessa rede que se instala em matéria de saúde pública surgem conflitos sobre a competência constitucional para regulamentação e implementação das medidas de enfrentamento da Pandemia de Covid-19.

Referidos conflitos foram levados ao Supremo Tribunal Federal para decidir, à luz da Constituição Federal de 1988, acerca das atribuições de cada uma das esferas de governo, em especial sobre a competência para regulamentação da quarentena e sua flexibilização (Ação Direta de Inconstitucionalidade $\mathrm{n}^{\circ}$ 6343/2020). O Supremo Tribunal Federal, em sede de liminar, conferiu interpretação conforme a Constituição a dispositivos da Lei nº 13.979/2020, com as seguintes conclusões: 
Após o voto do Ministro Marco Aurélio (Relator), que referendava o indeferimento da liminar; dos votos dos Ministros Alexandre de Moraes, Luiz Fux, Cármen Lúcia, Ricardo Lewandowski e Gilmar Mendes, que deferiam parcialmente a medida cautelar, a fim de, sem redução de texto, suspender em parte a aplicabilidade do art. $3^{\circ}$, VI, b, e $\S \S 6^{\circ}$ e $7^{\circ}$, II, da Lei ${ }^{\circ} 13.979 / 2020$ aos Estados, ao Distrito Federal e aos Municípios; e dos votos dos Ministros Edson Fachin e Rosa Weber, que deferiam parcialmente a medida cautelar requerida para conferir interpretação conforme ao inciso II do $\S 7^{\circ}$ do art. $3^{\circ}$ da Lei $n^{\circ} 13.979 / 2020$, a fim de explicitar que, nos termos do inciso I do art. 198 da Constituição e desde que amparadas em evidências científicas e nas recomendações da Organização Mundial da Saúde, Estados, Municípios e Distrito Federal podem determinar as medidas sanitárias de isolamento, quarentena, exumação, necropsia, cremação e manejo de cadáver, pediu vista dos autos o Ministro Dias Toffoli (Presidente). Falaram: pelo requerente, o Dr. Levi Borges de Oliveira Veríssimo; pelos interessados Presidente da República e Congresso Nacional, o Ministro José Levi Mello do Amaral Júnior, Advogado-Geral da União; e, pela interessada Federação Brasileira de Telecomunicações FEBRATEL, o Dr. Felipe Monnerat Solon de Pontes Rodrigues. Afirmou suspeição o Ministro Roberto Barroso. Ausente, justificadamente, o Ministro Celso de Mello. Plenário, 30.04.2020

(...)

O Tribunal, por maioria, concedeu parcialmente a cautelar para i) suspender parcialmente, sem redução de texto, o disposto no art. $3^{\circ}$, VI, b, e $\S \S 6^{\circ}$ e $7^{\circ}$, II, a fim de excluir estados e municípios da necessidade de autorização ou observância ao ente federal; e ii) conferir interpretação conforme aos referidos dispositivos no sentido de que as medidas neles previstas devem ser precedidas de recomendação técnica e fundamentada, devendo ainda ser resguardada a locomoção dos produtos e serviços essenciais definidos por decreto da respectiva autoridade federativa, sempre respeitadas as definições no âmbito da competência constitucional de cada ente federativo, nos termos do voto do Ministro Alexandre de Moraes, Redator para o acórdão, vencidos o Ministro Marco Aurélio (Relator), que trazia a referendo o indeferimento da medida liminar, e, em parte, os Ministros Edson Fachin e Rosa Weber, que deferiam parcialmente a medida cautelar para conferir interpretação conforme ao inciso II do $\S 7^{\circ}$ do art. $3^{\circ}$ da Lei $n^{\circ} 13.979 / 2020$. Afirmou suspeição o Ministro Roberto Barroso, ausente justificadamente. Presidência do Ministro Dias Toffoli. Plenário, 06.05.2020 (Ação Direta de Inconstitucionalidade nº 6343/2020)

\section{A decisão do Supremo vetou que o governo federal concentrasse em suas próprias} decisões a gestão da crise de saúde para regulamentar uma medida única em todo território nacional (como o fim da quarentena ou a liberação de inúmeras atividades como se essenciais fossem) ou, ainda, submeter as decisões das demais esferas de governo à autorização pela esfera federal (art. $3^{\circ}, \S 7^{\circ}$, da Lei Federal n $\left.{ }^{\circ} 13.979 / 2020\right)$.

Referido entendimento do Supremo Tribunal Federal gerou caloroso debate na esfera pública e surgiram interpretações, em especial do próprio Presidente da República ${ }^{2}$, no sentido de que tal decisão seria uma declaração de responsabilidade exclusiva dos Estados e

\footnotetext{
${ }^{2}$ No dia 8 de junho de 2020, o Presidente Jair Messias Bolsonaro utilizou suas redes sociais para o seguinte pronunciamento: "Lembro à Nação que, por decisão do STF, as ações de combate à pandemia (fechamento do comércio e quarentena, p.ex.) ficam sob total responsabilidade dos Governadores e dos Prefeitos" ('Cobre seu governador': qual a responsabilidade do governo federal no combate à pandemia?, BBC News Brasil, 2020).
} 
Municípios para a gestão do enfrentamento da Pandemia o que, como será demonstrado, é equivocado.

Para demonstrar o equívoco da mencionada interpretação, o presente artigo propõe uma análise pormenorizada do tema sob a ótica do Princípio Federativo e da distinção constitucional entre Competências Legislativas e Competências Administrativas.

Assim, o presente trabalho tem como objeto de estudo a aplicação do Princípio Federativo para solução de conflitos de competências constitucionais na gestão de crise da saúde pública no contexto da Pandemia de Covid-19. A análise foi feita conforme disposições da Constituição Federal de 1988 e da interpretação dada pelo Supremo Tribunal Federal ao julgar casos concretos que envolvem a temática.

Para fins metodológicos, foi realizado um recorte dentro do sistema de Seguridade Social brasileiro e para análise específica de suas disposições referentes à saúde pública, matéria que gerou maiores debates jurídicos no contexto de crise já descrito.

\section{O PRINCÍPIO FEDERATIVO COMO VETOR DE INTERPRETAÇÃO DA CONSTITUIÇÃO FEDERAL}

\subsection{A FEDERAÇÃO COMO FORMA ESSENCIAL PARA O ESTADO DEMOCRÁTICO DE DIREITO}

A Constituição Federal de 1988 adota a Federação como forma de Estado ${ }^{3}$. De fato, em seu artigo $1^{\circ}$ está declarado que "a República Federativa do Brasil, [é] formada pela união indissolúvel dos Estados e Municípios e do Distrito Federal”. Em seu artigo 18, é determinado que "a organização político-administrativa da República Federativa do Brasil compreende a União, os Estados, o Distrito Federal e os Municípios, todos autônomos, nos termos desta Constituição". Por fim, o artigo 60, $\S 4^{\circ}$, I, da Constituição veda a deliberação sobre proposta de emenda constitucional tendente a abolir a forma federativa de Estado.

Fica claro, portanto, a força normativa com que a Constituição, além de estipular a Federação como forma de Estado, trouxe garantias para sua a manutenção ao ponto de a elevar à estatura de Cláusula Pétrea. Isso significa que as características essenciais de uma Federação devem ser mantidas intactas ${ }^{4}$.

\footnotetext{
${ }^{3}$ Para uma análise histórica e crítica da origem e evolução do Federalismo Brasileiro até a Constituição de 1988 , $c f$. Elementos de Teoria Geral do Estado de Dalmo de Abreu Dallari (2016).

${ }^{4}$ Sobre a extensão da petrificação da forma federativa pelo constituinte de 1988 , cf. "O federalismo brasileiro, seus característicos e a vedação material contida no art. 60, §4, I” de Luiz Alberto David Araújo (1997).
} 
Nos próprios dispositivos antes citados, encontramos como características essenciais da Federação sua indissolubilidade, a divisão político-administrativa do território nacional em entes federados (União, Estados, Distrito Federal e Municípios) e a autonomia dos referidos entes.

Diante dessas normas constitucionais pode-se dizer que a Federação é essencial para a própria existência do Estado Democrático de Direito instituído pela Constituição de 1988 e, portanto, há um princípio básico, essencial à própria Constituição, que é o Princípio Federativo. Nesse sentido, o jurista português ANTÓNIO FRANCISCO DE SOUZA escreve ao analisar o caso de Portugal:

O Estado de direito democrático, categoria em que se insere o nosso país, é por definição um Estado descentralizado. A descentralização apresenta-se como um limite interno ao Estado de direito democrático, ou seja, é um limite préconstitucional ou supraconstitucional. Isto significa que quem elabora e aprova o Estatuto fundamental (Constituição) da sociedade ao aderir ao modelo 'Estado de direito democrático' fica desde logo obrigado a reconhecer nesse Estatuto, e suas futuras revisões, uma descentralização efectiva, o que significa dizer um verdadeiro poder local (e não um poder local fraco ou de simples fachada). Isto porque o Estado de direito, por natureza, reconhece que os assuntos próprios e específicos das localidades devem ser decididos pelas próprias localidades através de seus representantes. O poder local que aqui se trata é um poder originário, que brota das localidades e das respectivas populações e não um poder originário do Governo central, que depois é transferido para as localidades. (2000, pp. 30-31)

Tais lições foram corroboradas pela decisão proferida pelo Supremo Tribunal Federal ao analisar o contexto da Pandemia do coronavírus (covid-19) na ADI nº 6343/2020, nos seguintes termos: "as regras de distribuição de competências são alicerces do Federalismo e consagram a fórmula de divisão de centros de poder em um Estado de Direito (arts. $1^{\circ}$ e 18 da CF)".

E sobre o tema dos Princípios e suas funções, importante destacar a lição de CELSO ANTÔNIO BANDEIRA DE MELLO:

Princípio é, pois, por definição, mandamento nuclear de um sistema, verdadeiro alicerce dele, disposição fundamental que se irradia sobre diferentes normas, compondo-lhes o espírito e servindo de critério para exata compreensão e inteligência delas, exatamente porque define a lógica e a racionalidade do sistema normativo, conferindo-lhe a tônica que lhe dá sentido harmônico. (2007, p. 53)

Assim, o Princípio Federativo deve ser um vetor para a interpretação da Constituição em questões que envolvam as características essenciais da Federação. Com efeito, seria impossível à Assembleia Constituinte prever todas as questões futuras que poderiam, através

\footnotetext{
${ }^{5}$ Apesar das distinções da forma de Estado entre Portugal e Brasil, a lição citada é válida, pois a descentralização é ponto comum, apesar da forma diversa adotada entre os países. Sobre o tema em Portugal, $c f$. Teoria do Estado e da Constituição de Jorge Miranda (2015).
} 
da interpretação, atingir a indissolubilidade, a divisão político-administrativa e a autonomia dos entes federados. Assim, a Constituição consagra tais balizas como direção para a interpretação através do Princípio Federativo.

\subsection{A DiVisÃO POLÍTICO-ADMINISTRATIVA E A AUTONOMIA DOS ENTES FEDERADOS}

Sobre as características essenciais da Federação e quanto ao tema desse artigo merecem destaque a divisão político-administrativa e a autonomia dos entes federados.

A adoção constitucional da divisão político-administrativa em União, Estados, Distrito Federal e Municípios é compreendida em razão do extenso território nacional, bem como da diversidade de contextos sociais e econômicos que podem ser encontrados em todo o país. Não faria sentido, diante de tais fatos, concentrar o poder de gestão e a estrutura da Administração Pública de forma centralizada na União e, com isso, privilegiar o regramento jurídico e a prestação de serviços uniformizados, sem análise de peculiaridades locais, em todo o território nacional. Necessário, para o atendimento do interesse público, que referidas gestão e estrutura fossem divididas por meio de competência constitucionais com os demais entes da Federação e de acordo com as realidades regionais (Estados) e locais (Municípios).

E, para que tais entes federados possam bem exercer suas atribuições constitucionais, faz-se necessário garantir a autonomia de cada um deles. Autonomia no sentido de ter, no âmbito de sua governança, poder de decisão nos limites da Constituição e sem intervenção indevida de outro ente federado. Sem referida autonomia não há Federação, uma vez que um ente federado poderia ser submetido à intervenção dos demais e, assim, com a preponderância de um centro de poder, ser esvaziada a finalidade da própria Federação.

Sobre o tema "Federação: Soberania e Autonomia", FERNANDO WHITAKER DA CUNHA escreve:

\footnotetext{
A autonomia será sempre perceptível pela amplitude da capacidade normativa, dentro da descentralização, que, nas federações, é um posterius à autonomia e no unitarismo um prius à competência de regiões ou de províncias. E, indubitável, entrementes, que as transformações políticas têm estimulado federalismos em que há crescente ingerência do poder federal, nos Estados componentes. (1985, p. 80)
}

Assim, a divisão político-administrativa e a autonomia dos entes federados devem ser garantidas constitucionalmente contra a ingerência de um poder centralizador. Para tanto, são asseguradas aos entes federados as capacidades de auto-organização (autonomia administrativa), de elaborar sua própria legislação (autonomia política) e de arrecadar recursos para o exercício de suas atribuições constitucionais (autonomia financeira). 
A Constituição Federal assegura a autonomia dos entes federados ao prever citadas capacidades em forma de competências. Assim, o texto constitucional atribui aos entes federados competências administrativas (artigo 23, p. ex.), competências legislativas (artigo 24, p. ex.) e competências tributárias (artigos 153, 155 e 156, p. ex.) ${ }^{6}$.

As possíveis relações entre o regime federalista e a divisão de competências no sentido de maior centralização ou maior descentralização do poder são resumidas por RAUL MACHADO HORTA nos seguintes termos:

\begin{abstract}
A repartição de competências poderá acentuar a centralização, concentrando na União a maior soma dos poderes e competências, como se fez na Constituição Federal de 1967, ou consagrar a descentralização, reduzindo poderes centrais e ampliando os poderes estaduais, ou ainda, afastando-se de soluções extremas, operar a dosagem das competências federais, estaduais e municipais, de modo a instaurar o equilíbrio entre o ordenamento central da Federação e os ordenamentos parciais, como me parece ser a tendência dominante na Constituição Federal de 1988. No primeiro caso, a centralização de poderes gera o federalismo centrípeto; no segundo, a descentralização conduz ao federalismo centrífugo e, no terceiro, implanta-se o federalismo de equilíbrio, que identifica modelo contemporâneo da forma federal de Estado. (1996, p. 24)
\end{abstract}

O Supremo Tribunal Federal, na decisão objeto de análise por este trabalho, deixa claro que a manutenção do citado Federalismo de equilíbrio é essencial para o enfrentamento da Pandemia de Covid-19:

1. Em momentos de acentuada crise, o fortalecimento da união e a ampliação de cooperação entre os três poderes, no âmbito de todos os entes federativos, são instrumentos essenciais e imprescindíveis a serem utilizados pelas diversas lideranças em defesa do interesse público, sempre com o absoluto respeito aos mecanismos constitucionais de equilíbrio institucional e manutenção da harmonia e independência entre os poderes, que devem ser cada vez mais valorizados, evitandose o exacerbamento de quaisquer personalismos prejudiciais à condução das políticas públicas essenciais ao combate da pandemia de COVID-19.

2. A gravidade da emergência causada pela pandemia do corona vírus (COVID-19) exige das autoridades brasileiras, em todos os níveis de governo, a efetivação concreta da proteção à saúde pública, com a adoção de todas as medidas possíveis e tecnicamente sustentáveis para o apoio e manutenção das atividades do Sistema Único de Saúde. (Ação Direta de Inconstitucionalidade nº 6343/2020)

E o desrespeito do modelo de divisão adotado com a invasão de competência de um ente federado por outro é ato eivado de grave vício de inconstitucionalidade, seja por abuso no exercício da própria competência, seja por exceder os limites dos poderes conferidos, conforme destacado por MARCELO FIGUEIREDO:

No Estado Federal, a inconstitucionalidade dos atos do Poder Público pode se dar no âmbito da própria competência dos entes federados, por ação (inconstitucionalidade por ação), seja por abuso no exercício da própria competência, seja por exceder os

\footnotetext{
${ }^{6}$ Sobre a classificação das competências constitucionais, $c f$. "Curso de Direito Constitucional", de ANDRÉ RAMOS TAVARES (2018).
} 
limites dos poderes conferidos (excesso de poder), seja por desvio de finalidade, ou desvio de poder, ou por omissão (inconstitucionalidade por omissão); a inconstitucionalidade pode se dar, ainda, fora do âmbito da própria competência, em razão da tentativa de usurpação ou invasão de competência alheia, que constitucionalmente não pertença ao ente federado. $\mathrm{O}$ abuso dos poderes constitucionalmente outorgados aos entes federados, sob vários matizes em que se pode configurar, por representar ameaça inadmissível aos direitos fundamentais, à supremacia da ordem constitucional e de seus valores e princípios, deslegitima o poder e a autoridade, descaracterizando a atividade pública, que passa a se caracterizar como atividade ilícita e, como tal, pode desestabilizar o próprio Estado de Direito. (2019, p. 239-240)

Assim, dentro do federalismo de equilíbrio não existe hierarquia entre os entes federados e a invasão de competência de um ente federado por outro fere o Princípio Federativo, uma vez que atinge a autonomia do ente usurpado.

Para o objeto deste trabalho, interessa diretamente o estudo das competências administrativas e legislativas na gestão da saúde pública, que serão tratadas a seguir.

\title{
3 COMPETÊNCIAS CONSTITUCIONAIS NA GESTÃO DA SAÚDE PÚBLICA
}

\subsection{COMPETÊNCIA LEGISLATIVA E COMPETÊNCIA ADMINISTRATIVA: DISTINÇÕES NECESSÁRIAS}

Como descrito na introdução, para combate à Pandemia de Covid-19, o governo federal foi impedido de concentrar em suas próprias decisões a gestão da crise de saúde para determinar uma medida única em todo território nacional ou, ainda, submeter as decisões das demais esferas de governo à autorização pela esfera, conforme decisão do Supremo Tribunal Federal:

\begin{abstract}
Não compete, portanto, ao Poder Executivo federal afastar, unilateralmente, as decisões dos governos estaduais, distrital e municipais que, no exercício de suas competências constitucionais, adotaram ou venham a adotar, no âmbito de seus respectivos territórios, importantes medidas restritivas como a imposição de distanciamento ou isolamento social, quarentena, suspensão de atividades de ensino, restrições de comércio, atividades culturais e à circulação de pessoas, entre outros mecanismos reconhecidamente eficazes para a redução do número de infectados e de óbitos, como demonstram a recomendação damos (Organização Mundial de Saúde) e vários estudos técnicos científicos, como por exemplo, os estudos realizados pelo Imperial College of London, a partir de modelos matemáticos (The Global Impact of COVID-19 and Strategies for Mitigation and Suppression, vários autores; Impact of non-pharmaceutical interventions (NPIs) to reduce COVID-19 mortality andhealthcare demand, vários autores) (ADI nº 6343/2020) ${ }^{7}$
\end{abstract}

\footnotetext{
${ }^{7}$ Exemplo de medida concreta de aplicação do referido entendimento do Supremo Tribunal Federal é encontrado na Arguição de Descumprimento de Preceito Fundamental n ${ }^{\circ} 669$ na qual se discute a constitucionalidade de ato administrativo praticado pelo Governo Federal por meio da Secretaria de Comunicação da Presidência da República com a contratação de empresa de publicidade para elaboração de campanha intitulada "O Brasil não pode parar". A ideia central da referida campanha de âmbito nacional contraria medidas restritivas como a imposição de distanciamento ou isolamento social, quarentena, suspensão de atividades de ensino, restrições de
} 
Assim, questiona-se: tal entendimento trata da competência constitucional administrativa ou legislativa? A resposta é que trata de ambas, tanto a competência legislativa como a competência administrativa são técnicas que incidem, cada qual em sua esfera constitucional, na gestão da crise de saúde pública:

Em relação à saúde e assistência pública, a Constituição Federal consagra a existência de competência administrativa comum entre União, Estados, Distrito Federal e Municípios (art. 23, II e IX, da CF), bem como prevê competência concorrente entre União e Estados/Distrito Federal para legislar sobre proteção e defesa da saúde (art. 24, XII, da CF); permitindo aos Municípios suplementar a legislação federal e a estadual no que couber, desde que haja interesse local (art. 30, II, da CF); e prescrevendo ainda a descentralização político-administrativa do Sistema de Saúde (art. 198, CF, e art. $7^{\circ}$ da Lei 8.080/1990), com a consequente descentralização da execução de serviços, inclusive no que diz respeito às atividades de vigilância sanitária e epidemiológica (art. $6^{\circ}$, I, da Lei 8.080/1990) (ADI n ${ }^{\circ}$ 6343/2020)

A competência constitucional administrativa pode ser definida como a atribuição que a Constituição reconhece para determinado ente federado implementar materialmente uma atividade ou um serviço público. Por sua vez, a competência constitucional legislativa é a atribuição dada pela Constituição a determinado ente Federado para regulamentar normativamente determinada matéria.

Pois bem. Num primeiro momento, o Supremo Tribunal Federal decidiu sobre a competência para regulamentação das medidas de enfrentamento da Pandemia, ou seja, decidiu sobre uma competência normativa, uma competência constitucional legislativa:

De fato, a decisão do Supremo tomou como base o artigo $24, \mathrm{XII}, \S 1^{\circ}$ a $\S 4^{\circ}$ e art. 30 , I e II, da Constituição Federal, que tem a seguinte redação:

\footnotetext{
Art. 24. Compete à União, aos Estados e ao Distrito Federal legislar concorrentemente sobre:

(...)

XII - previdência social, proteção e defesa da saúde;

(...)

$\S 1^{\circ}$ No âmbito da legislação concorrente, a competência da União limitar-se-á a estabelecer normas gerais.

$\S 2^{\circ}$ A competência da União para legislar sobre normas gerais não exclui a competência suplementar dos Estados.

$\S 3^{\circ}$ Inexistindo lei federal sobre normas gerais, os Estados exercerão a competência legislativa plena, para atender a suas peculiaridades.

$\S 4^{\circ}$ A superveniência de lei federal sobre normas gerais suspende a eficácia da lei estadual, no que lhe for contrário.
}

comércio, atividades culturais e à circulação de pessoas, entre outros, tomadas com base nos interesses regionais e locais pelos governos estaduais e municipais, respectivamente. 


\author{
Art. 30. Compete aos Municípios: \\ I - legislar sobre assuntos de interesse local; \\ II - suplementar a legislação federal e a estadual no que couber;
}

No exercício da competência legislativa concorrente a União tem a atribuição de editar normas gerais e os Estados, por sua vez, apresentam competência suplementar ou plena (caso não existam norma gerais editadas pela União). É certo também que o exercício da competência suplementar ou plena pelos Estados é limitado ao interesse regional, ou seja, às peculiaridades presentes naquele determinado ente federativo. $\mathrm{O}$ mesmo regramento se aplica aos Municípios, porém limitados a interesse local. Por fim, não pode a União, no exercício da competência para editar normas gerais, invadir o campo de atuação das leis estaduais e municipais, ou seja, não pode legislar questões específicas que destoem da condição de normas gerais. Não há hierarquia entre as normas discutidas, mas sim campos de atuação diferentes de acordo com o interesse envolvido.

Nesse sentido, ensina GERALDO ATALIBA, que as Leis Nacionais:

Dominam o próprio campo constitucional, em caráter privativo, prevalecendo - em razão da delimitação constitucional, e não de hierarquia - sobre tentativas das demais leis de lhes invadir esta faixa, não podem estender-se validamente aos objetos próprios da legislação federal, estadual e municipal. (1980, p. 58)

Em complemento, pautado no Princípio Federativo, ROQUE ANTONIO CARRAZA leciona que:

\footnotetext{
Desdobrando melhor estas ideias, no Brasil, por obra e graça do princípio federativo - verdadeira coluna mestra de nosso sistema jurídico -, convivem harmonicamente (e nisto estamos com Kelsen) a ordem jurídica global (o Estado Brasileiro) e as ordens jurídicas parciais, central (a União) e periféricas (os Estados-membros). Esta múltipla incidência só é possível por força da cuidadosa discriminação de competências, levada a efeito pela Constituição da República. (2008, p. 140)
}

Assim, vê-se que a citada decisão do Supremo Tribunal Federal apenas esclareceu em interpretação conforme a Constituição a divisão e os limites do exercício da competência legislativa concorrente.

Evidentemente, a competência legislativa ora analisada não se confunde com a competência administrativa, que diz respeito ao ente federado que recebe a atribuição constitucional para implementar materialmente determinada atividade ou serviço público.

Num segundo momento, a decisão do Supremo Tribunal Federal também diz respeito à competência administrativa comum. Quanto à gestão da saúde pública, a competência 
administrativa é comum, ou seja, é atribuída simultaneamente a todos os entes federados, nos termos dos artigos 23, II, 196 e 198, I, da Constituição Federal:

Art. 23. É competência comum da União, dos Estados, do Distrito Federal e dos Municípios:

II - cuidar da saúde e assistência pública, da proteção e garantia das pessoas portadoras de deficiência;

(...)

Art. 196. A saúde é direito de todos e dever do Estado, garantido mediante políticas sociais e econômicas que visem à redução do risco de doença e de outros agravos e ao acesso universal e igualitário às ações e serviços para sua promoção, proteção e recuperação.

(...)

Art. 198. As ações e serviços públicos de saúde integram uma rede regionalizada e hierarquizada e constituem um sistema único, organizado de acordo com as seguintes diretrizes:

I - descentralização, com direção única em cada esfera de governo;

Importante destacar também que o Sistema Único de Saúde previsto no art. 198 da Constituição Federal é responsável, dentre outras medidas, por executar as ações de vigilância sanitária e epidemiológica (artigo 200, II, da Constituição); assim, o mesmo sistema que se aplica à prestação dos serviços de saúde, também incide sobre as medidas de enfrentamento da epidemia de Covid-19.

\subsection{COMPETÊNCIA LEGISLATIVA CONCORRENTE E COMPETÊNCIA ADMINISTRATIVA COMUM COMO TÉCNICAS DE GESTÃO PARA O SISTEMA ÚNICO DE SAÚDE BRASILEIRO}

Em resumo, em matéria de saúde pública temos:

(a) competência legislativa concorrente: competência normativa para regulamentação das medidas de enfrentamento da pandemia; é concorrente e deve prevalecer o critério do interesse nacional e regional para, na prática, a fixação da competência federal ou estadual, restando aos municípios a competência suplementar.

(b) competência administrativa comum: atribuição de exercer materialmente determinada atividade ou serviço público de saúde em prol da população; é comum e deve ser exercida através do Sistema Único de Saúde, em rede regionalizada e hierarquizada e organizada por meio da descentralização por todas as esferas de governo.

Apesar de não se confundirem, tanto a competência legislativa concorrente como a competência administrativa comum podem ser apontadas como técnicas de gestão para maior eficiência diante da extensão territorial brasileira, bem como das diferentes realidades sociais e econômicas encontradas em nosso país. 
Esse entrelaçamento entre as competências legislativas concorrentes e administrativas comuns especificamente no caso do combate do Covid-19 é destacado no artigo "COVID-19: análise crítica da distribuição constitucional de competências" de RAFAEL MAFFINI, professor da Universidade Federal do Rio Grande do Sul:

\begin{abstract}
A competência da União para editar normas gerais em matéria de saúde (art. 24, XII, CF) deve ser devidamente articulada com a competência administrativa comum de todos os entes federados (art. 23, II, da CF). No exercício das competências administrativas, os entes federativos devem primar por uma atuação cooperada, mas havendo divergências entre as medidas empregadas, sobretudo as medidas de quarentena, devem predominar aquelas que estiverem mais bem fundamentadas em critérios científicos, atendando-se para as respectivas realidades regionais ou locais sobre as quais incidem, minimizando, pois, interferências pessoais e ideológicas. (2021, p. 376)
\end{abstract}

Referidas técnicas de competência permitem que haja uma uniformização da legislação e da prestação dos serviços públicos de saúde de acordo com o interesse nacional por meio das normas gerais e atuação administrativa da União, sem que isso impeça que as peculiaridades de cada ente federativo sejam analisadas e especificadas em legislação local, com o respeito das normas gerais editadas, bem como medidas administrativas materiais sejam implementadas de acordo com as mesmas peculiaridades.

\title{
4 COMBATE À PANDEMIA DE COVID-19 E CONFLITO DE COMPETÊNCIAS
}

Como visto, uma rede de competências legislativas concorrentes e administrativas comuns se instala entre as esferas de governo em matéria de saúde pública e, na prática, há conflitos para regulamentação e implementação das medidas de enfrentamento da Pandemia de Covid-19.

O principal conflito que pode ser apresentado diz respeito à competência quanto às medidas de isolamento e de quarentena.

A Lei Federal $n^{\circ} 13.979 / 2020$ dispõe sobre as medidas para enfrentamento da emergência de saúde pública de importância internacional decorrente do Covid-19. Trata-se de ato normativo emanado da União em exercício de sua competência legislativa em matéria de saúde pública que, como vimos, é concorrente; portanto, referida Lei traz as normas gerais sobre as medidas de enfrentamento da Pandemia de Covid-19.

Merecem destaque os artigos $2^{\circ}$ e $3^{\circ}$ da Lei Federal $n^{\circ} 13.979 / 2020$, ao prescreverem que: 
I - isolamento: separação de pessoas doentes ou contaminadas, ou de bagagens, meios de transporte, mercadorias ou encomendas postais afetadas, de outros, de maneira a evitar a contaminação ou a propagação do coronavírus; e

II - quarentena: restrição de atividades ou separação de pessoas suspeitas de contaminação das pessoas que não estejam doentes, ou de bagagens, contêineres, animais, meios de transporte ou mercadorias suspeitos de contaminação, de maneira a evitar a possível contaminação ou a propagação do coronavírus.

Art. $3^{\circ}$ Para enfrentamento da emergência de saúde pública de importância internacional decorrente do coronavírus, as autoridades poderão adotar, no âmbito de suas competências, dentre outras, as seguintes medidas:

I - isolamento;

II - quarentena;

(...)

$\S 5^{\circ}$ Ato do Ministro de Estado da Saúde:

I - disporá sobre as condições e os prazos aplicáveis às medidas previstas nos incisos I e II do caput deste artigo;

(...)

$\S 7^{\circ}$ As medidas previstas neste artigo poderão ser adotadas:

I - pelo Ministério da Saúde, exceto a constante do inciso VIII do caput deste artigo; II - pelos gestores locais de saúde, desde que autorizados pelo Ministério da Saúde, nas hipóteses dos incisos I, II, V e VI do caput deste artigo;

III - pelos gestores locais de saúde, nas hipóteses dos incisos III, IV e VII do caput deste artigo.

IV - pela Anvisa, na hipótese do inciso VIII do caput deste artigo.

(...)

Dos dispositivos citados vê-se que as medidas de enfrentamento da Pandemia de Covid-19 podem ser determinadas pelas autoridades federais, estaduais e municipais no âmbito de suas competências. Porém, chama a atenção as disposições que submetem os gestores locais de saúde à autorização pelo Ministério da Saúde para determinação da quarentena $\left(\$ 7^{\circ}, \mathrm{II}\right)$, bem como às condições e prazos fixados por ato do Ministra da Saúde $\left(\S 5^{\circ}, \mathrm{I}\right)$.

Nesse ponto, merece destaque as advertências feitas pelos autores LIMA VENTURA, ABUJAMRA AITH E RACHED, pesquisadores da Universidade de São Paulo e da Fundação Getúlio Vargas, ao analisar a Lei Federal no 13.979/2020 no artigo “A emergência do novo coronavírus e a 'lei de quarentena' no Brasil':

A lei de quarentena mantém os traços essenciais da legislação precedente, quais sejam a elaboração reativa e casuística de instrumentos normativos; a fragmentação do ordenamento jurídico numa diversidade de instrumentos cuja consistência hierárquica pode ser questionada; a ausência do imprescindível debate democrático; e a pendência de normatização de numerosos detalhes decisivos para a correta implementação da lei, constatado um ainda insuficiente exercício do poder regulamentar. (2021, p. 131) 
Para o objeto deste trabalho, interessa aprofundar a questão no tocante à "fragmentação do ordenamento jurídico numa diversidade de instrumentos cuja consistência hierárquica pode ser questionada". O que se coloca em discussão é a constitucionalidade das restrições da norma federal ao exercício da competência constitucional dos entes federados, submetidos seus atos, pela letra da lei, à chancela do Ministério da Saúde, órgão do governo federal. Tais disposições são compatíveis com o Princípio Federativo e a divisão de competências constitucionais?

Sobre a questão o Supremo Tribunal Federal concluiu que:

Os condicionamentos impostos pelo art. $3^{\circ}, \mathrm{VI}$, "b", $\S \S 6^{\circ}, 6^{\circ}-\mathrm{A}$ e $7^{\circ}$,II, da Lei 13.979/2020, aos Estados e Municípios para a adoção de determinadas medidas sanitárias de enfrentamento à pandemia do COVID-19, restringem indevidamente o exercício das competências constitucionais desses entes, em detrimento do pacto federativo (...) Medida Cautelar parcialmente concedida para: (a) suspender, sem redução de texto, o art. $3^{\circ}$, VI, "b", e $\S \S 6^{\circ}, 6^{\circ}$-A e $7^{\circ}$, II, excluídos Estados e Municípios da exigência de autorização da União, ou obediência a determinação de órgãos federais, para adoção de medidas de restrição à circulação de pessoas. (ADI $\left.n^{\circ} 6343 / 2020\right)$

Como visto, em decorrência do Princípio Federativo é imprescindível garantir a autonomia dos entes federados para que possam exercer suas atribuições constitucionais com sucesso. E a autonomia aqui consignada diz respeito ao poder de gestão por decisões próprias, sem intervenção indevida de outro ente federado, desde que a decisão esteja nos limites da Constituição.

Também necessário recordar que referidos limites estão estabelecidos pela divisão de competências constitucionais, seja a competência legislativa concorrente para regulamentação das medidas de enfrentamento da pandemia, seja a competência administrativa comum para exercer materialmente determinada atividade ou serviço público de saúde em prol da população.

No caso da competência legislativa concorrente, sua fixação é determinada pelo critério do interesse nacional ou regional com a finalidade de atender as peculiaridades locais para combater a Pandemia. Por esse motivo, a própria Lei Federal $n^{\circ} 13.979 / 2020$ determina em seu artigo $3^{\circ}, \S 1^{\circ}$, que:

$\S 1^{\circ}$ As medidas previstas neste artigo somente poderão ser determinadas com base em evidências científicas e em análises sobre as informações estratégicas em saúde e deverão ser limitadas no tempo e no espaço ao mínimo indispensável à promoção e à preservação da saúde pública.

É fato que informações estratégicas para gestão da crise de saúde pública dizem respeito a dados específicos de cada região do país limitadas a esse espaço determinado e que 
não refletem um contexto epidemiológico único no território nacional todo, portanto, critérios de interesse regional e não nacional de regulamentação da questão.

No mesmo sentido aqui defendido, a Portaria no 356/2020, do Ministro da Saúde, determina em seu artigo $4^{\circ}, \S^{\circ}$, que:

A medida de quarentena será determinada mediante ato administrativo formal e
devidamente motivado e deverá ser editada por Secretário de Saúde do Estado, do
Município, do Distrito Federal ou Ministro de Estado da Saúde ou superiores em
cada nível de gestão.

Em razão disso, o Supremo Tribunal Federal vetou, acertadamente, que o governo federal determinasse uma medida única em todo território nacional, ou submetesse ao crivo do Ministério da Saúde as decisões das autoridades locais (Ação Direta de Inconstitucionalidade $n^{\circ}$ 6343/2020). De fato, a competência para tal regulamentação é legislativa concorrente e para implementação das medidas há competência administrativa comum. Em ambas deve prevalecer o critério do interesse nacional e regional.

Essa interpretação conforme a Constituição realizada pelo Supremo às disposições que submetem os gestores locais de saúde à autorização pelo Ministério da Saúde para determinação da quarentena garante a autonomia dos entes federados que recebem competência constitucional para decidir sem intervenção das outras esferas - sempre, é claro, dentro dos limites constitucionais e de acordo com as normas gerais fixadas pela esfera federal.

Importante ressaltar que referido entendimento do Supremo Tribunal Federal diz respeito à competência legislativa concorrente e à competência administrativa comum em matéria de saúde pública.

Repita-se, para finalizar, que a competência administrativa em matéria de saúde pública é comum, ou seja, é atribuída simultaneamente a todos os entes federados a função de exercer materialmente determinada atividade ou serviço público de saúde em prol da população, por meio do Sistema Único de Saúde, uma rede regionalizada e descentralizada por todas as esferas de governo.

Vê-se, ainda, que o Supremo Tribunal Federal deixa expresso em sua decisão que "a União tem papel central, primordial e imprescindível de coordenação em uma pandemia internacional nos moldes que a própria Constituição estabeleceu no SUS" (Ação Direta de Inconstitucionalidade $\mathrm{n}^{\circ}$ 6343/2020).

Assim, em nenhum momento foi afastada a responsabilidade dos gestores federais no combate à Pandemia, pelo contrário, tal responsabilidade foi reafirmada em conjunto com a 
atuação dos demais gestores locais. Portanto, absolutamente equivocada a interpretação de que a decisão do Supremo foi uma declaração de responsabilidade exclusiva dos Estados e Municípios para o enfrentamento da Pandemia de Covid-19.

\section{CONCLUSÕES}

Diante de todo o exposto, o estudo realizado permite as seguintes conclusões:

I - A Federação é essencial para a própria existência do Estado Democrático de Direito instituído pela Constituição de 1988 e, portanto, há um princípio básico, essencial à própria Constituição, que é o Princípio Federativo;

II - O Princípio Federativo é um vetor para a interpretação da Constituição em questões que envolvam as características essenciais da Federação;

III - Para que os entes federados possam bem exercer suas atribuições constitucionais, faz-se necessário garantir a autonomia de cada um deles. Autonomia no sentido de ter poder de decisão nos limites da Constituição e sem intervenção indevida de outro ente federado. Assim, a invasão de competência de um ente federado por outro fere o Princípio Federativo, uma vez que atinge a autonomia do ente usurpado.

IV - Ao examinar os casos de conflito de competências constitucionais na Pandemia de covid-19, o Supremo Tribunal Federal decidiu sobre a competência para regulamentação das medidas de enfrentamento da Pandemia, ou seja, decidiu sobre uma competência normativa, uma competência constitucional legislativa concorrente; bem como decidiu sobre uma competência administrativa comum, ou seja, para os entes federados exercerem materialmente determinada atividade ou serviço público;

V- No caso da competência legislativa concorrente, sua fixação é determinada pelo critério do interesse nacional ou regional com a finalidade de atender as peculiaridades locais para combater a Pandemia, o que foi reconhecido pela interpretação conforme a Constituição que o Supremo realizou sobre a Lei Federal no 13.979/2020.

VI - Assim, garante-se a autonomia e o exercício da competência legislativa dos entes federados ao se considerar que informações estratégicas em saúde dizem respeito a dados específicos de cada região do país limitadas a esse espaço determinado e que não reflete um contexto epidemiológico único no território nacional todo, portanto, critérios de interesse regional e não nacional de regulamentação da questão.

VII - No tocante à competência administrativa comum em matéria de saúde pública, absolutamente equivocada é a interpretação de que a decisão do Supremo foi uma declaração 
de responsabilidade exclusiva dos Estados e Municípios para o enfrentamento da Pandemia de Covid-19, pelo contrário, a prestação material do serviço de saúde deve ser concretizada por meio do Sistema Único de Saúde, uma rede regionalizada e descentralizada por todas as esferas de governo.

\section{REFERÊNCIAS BIBLIOGRÁFICAS}

ARAUJO, L. A. D. O federalismo brasileiro, seus característicos e a vedação material contida no art. $60, \S 4^{\circ}$, I. Revista de Direito Constitucional e Internacional. São Paulo, p. 18-145, jan./mar., 1997.

ATALIBA, G. Regime Constitucional e Leis Nacionais e Leis Federais. Revista de Direito Público. São Paulo, p. 53-82, jan./mar., 1980.

BANDEIRA DE MELLO, C.A. Curso de Direito Administrativo. 25. ed. São Paulo: Malheiros, 2007.

BRASIL. Ação Direta de Inconstitucionalidade $n^{0}$ 6343. Brasília: STF, 2019. Disponível em: $<$ http://portal.stf.jus.br/processos/detalhe.a sp?incidente $=5881008>$. Acesso em: 29.07.2020.

BRASIL. Arguição de Descumprimento a Preceito Fundamental $n^{\circ}$ 669. Brasília: STF, 2019. Disponível em: < http://portal.stf.jus.br/processos/detalhe.asp ?incidente $=5884084>$. Acesso em: 28.04.2021.

BRASIL. Lei Federal $n^{0} 13.979$ de 6 de fevereiro de 2020. Brasília: Congresso Nacional, 2020. Disponível em: < http://www.planalto.gov.br/ccivil_03/_ato2019 -2022/2020/lei/113979.htm>. Acesso em: 29.07.2020.

BRASIL. Portaria no 356 de 11 de março de 2020. Brasília: Ministério da Saúde, 2020. Disponível em: < https://www.in.gov.br/en/web/dou/-/portaria-n356-de-11-de-marco-de-2020-247538346>.

Acesso em: 29.07.2020.

BONAVIDES, P. Curso de Direito Constitucional. $32^{\mathrm{a}}$. ed. São Paulo: Malheiros, 2017.

CARRAZA, R. A. Curso de Direito Constitucional Tributário. 24 ed. São Paulo: Malheiros, 2008.

'COBRE seu governador': qual a responsabilidade do governo federal no combate à pandemia?. BBC News Brasil, São Paulo, 06 de julho de 2020. Caderno Educação, p. 41. Disponível em: < https://www.bbc.com/portuguese/brasil53244465>. Acesso em: 29.07.2020.

CUNHA, F. W. da. Federação: Soberania e Autonomia. Revista de Direito Público. São Paulo, p. 73-145, jan./mar., 1985.

CANOTILHO, J. J. G. Direito Constitucional e Teoria da Constituição. $7^{\text {a }}$. ed. Coimbra: Almedina, 2003.

DALlARI, D. A. Elementos de Teoria Geral do Estado. 33a . ed. São Paulo, Saraiva, 2016.

FIGUEIREDO, M. Direito Constitucional: estudos interdisciplinares sobre federalismo, democracia e Administração Pública. 2 ed. Belo Horizonte: Fórum, 2019.

HORTA, R. M. Tendências Atuais da Federação Brasileira. Revista de Direito 
Constitucional e Internacional. São Paulo, p. 16-33, jul./set., 1996.

LIMA VENTURA, D.F.; ABUJAMRA AITH, F.M.; RACHED, D. H. A emergência do novo coronavírus e a"lei de quarentena"no Brasil. Revista Direito e Praxis. Rio de Janeiro, p. 102-138, v. 12, n. 1, 2021. Disponível em: < https://www.e-

Publicacoes.uerj.br/index.php/revistaceaju/ article/view/49180 >. Acesso em: 28.04.2021.

MAFFINI, R. COVID-19: análise crítica da distribuição constitucional de competências. Revista Direito e Praxis. Rio de Janeiro, p. 353-378, v. 12, n. 1,
2021. Disponível em: <https://www.scielo.br/pdf/rdp/v12n1/217 9-8966-rdp-12-01-353.pdf >. Acesso em: 28.04.2021.

MIRANDA, J. Teoria do Estado e da Constituição. $4^{\mathrm{a}}$. ed. Rio de Janeiro: Forense, 2015.

SOUZA, A. F. de. A regionalização no contexto do Estado de Direito Democrático e o caso Português. Revista de Direito Constitucional e Internacional. São Paulo, p. 30-55, jan./mar., 2000.

TAVARES, A. R. Curso de Direito Constitucional. 16 . ed. São Paulo: Saraiva, 2018.

\title{
FEDERATIVE PRINCIPLE AND CONSTITUTIONAL COMPETENCES CONFLICTS: AN ANALYSIS FROM THE PUBLIC HEALTH CRISIS MANAGEMENT APPROACH IN COVID-19 PANDEMIC
}

\section{Arilson Garcia Gil}

How to cite this article: GIL, Arilson Garcia. Princípio federativo e conflitos de competências constitucionais: uma análise sob o enfoque da gestão de crise da saúde pública na Pandemia de Covid-19. Revista de Ciências do Estado. Belo Horizonte: v. 6, n. 1, 2021, e25986. ISSN: 2525-8036.

\begin{abstract}
This paper analyses the conflict of constitutional competencies established between federal entities in the Covid-19 Pandemic and the interpretation given by the Federal Supreme Court on the subject. The work starts from the study of the Federative Principle as a vector of interpretation of the Constitution and goes through the analysis of the division of constitutional competencies and its importance for the autonomy of the federated entities. The provisions of Federal Law 13,979/2020 are also analyzed, which generated debate on the conflict of competencies for regulation and action in the Pandemic. In the course of the research it was verified that the constitutional norms that deal with public health and the infraconstitutional ones edited to face the Pandemic of Covd-19 configure attribution and exercise of concurrent legislative competence and common administrative competence. Finally, it was about the interpretation according to the Constitution given to the Federal Law $\mathrm{n}^{\circ}$ $13.979 / 2020$ by the Federal Supreme Court, when declaring the competence of the States and Cities to regulate measures such as quarantine, independent of authorization of the federal sphere. It is concluded by the adequacy of the referred decision to the constitutional federalism, besides being clarified that the referred decision did not configure recognition of exclusive responsibility of the States and the Cities in the combat to the Covid-19, before the distinction between legislative competence and administrative competence, as well as the structuring of the Unique System of Health with participation of all the federated entities.
\end{abstract}


Keywords: Federative Principle. Public Health. Crises Management. Legislative Competence. Administrative Competence. 